\title{
Parameterization of the snow-covered surface albedo in the Noah-MP Version 1.0 by implementing vegetation effects
}

\author{
Sojung Park ${ }^{1,3,4}$ and Seon Ki Park ${ }^{1,2,3,4}$ \\ ${ }^{1}$ Department of Atmospheric Science and Engineering, Ewha Womans University, Seoul, Republic of Korea \\ ${ }^{2}$ Department of Environmental Science and Engineering, Ewha Womans University, Seoul, Republic of Korea \\ ${ }^{3}$ Center for Climate/Environment Change Prediction Research, Ewha Womans University, Seoul, Republic of Korea \\ ${ }^{4}$ Severe Storm Research Center, Ewha Womans University, Seoul, Republic of Korea \\ Correspondence to: Seon Ki Park (spark@ewha.ac.kr)
}

Received: 6 February 2015 - Published in Geosci. Model Dev. Discuss.: 13 April 2015

Revised: 25 January 2016 - Accepted: 3 March 2016 - Published: 17 March 2016

\begin{abstract}
Snow-covered surface albedo varies depending on many factors, including snow grain size, snow cover thickness, snow age, forest shading factor, etc., and its parameterization is still under great uncertainty. For the snow-covered surface condition, albedo of forest is typically lower than that of short vegetation; thus snow albedo is dependent on the spatial distributions of characteristic land cover and on the canopy density and structure. In the Noah land surface model with multiple physics options (Noah-MP), almost all vegetation types in East Asia during winter have the minimum values of leaf area index (LAI) and stem area index (SAI), which are too low and do not consider the vegetation types. Because LAI and SAI are represented in terms of photosynthetic activeness, stem and trunk in winter are not well represented with only these parameters. We found that such inadequate representation of the vegetation effect is mainly responsible for the large positive bias in calculating the winter surface albedo in the Noah-MP. In this study, we investigated the vegetation effect on the snow-covered surface albedo from observations and improved the model performance by implementing a new parameterization scheme. We developed new parameters, called leaf index (LI) and stem index (SI), which properly manage the effect of vegetation structure on the snow-covered surface albedo. As a result, the Noah-MP's performance in the winter surface albedo has significantly improved - the root mean square error is reduced by approximately $69 \%$.
\end{abstract}

\section{Introduction}

Snow albedo is very important in calculating the energy budget at the land surface, but the vegetation effects on adequate parameterization of the snow surface albedo are still under great uncertainty. Vegetation influences both snow cover and albedo that can be summarized in three points. First, the canopy changes snow depth because leaves and branches can intercept part of the snow. Second, vegetation generally has a larger roughness than bare soil. Normally just a small amount of snow is sufficient to cover bare soil, resulting in high albedo. However, over short vegetation, the same snow amount cannot cover all vegetation because some individual vegetation can be higher than snow depth. Thus, in case of snow, total albedo over short vegetation is lower than that over bare soil. With the same amount of snow, total albedo becomes much lower over forests. This can be the case due to litter in snow beneath trees (Hardy et al., 2000); however, it is mostly related to snow depth to cover vegetation. For example, in order to fully cover a tree $10 \mathrm{~m}$ high, snow should accumulate to more than $10 \mathrm{~m}$. Although the tree tops can be covered by snow with an accumulated amount lower than $10 \mathrm{~m}$, the shading effect of tree through its structure still remains at non-zero solar zenith angle. Lastly, vegetation can change heat flux with different temperature from bare soil. Moreover, vegetation changes the longwave radiation as a tree re-emits radiation downwards. For instance, when the air temperature is just below $0^{\circ} \mathrm{C}$, there is no frost and snow melts earlier under trees. 
Previous studies have addressed the apparent relationship between snow cover over different vegetation types and the snow surface albedo through field measurements and satellite observations as well (Henderson-Sellers and Wilson, 1983; Jin et al., 2002; Gao et al., 2005). Gao et al. (2005) found that the maximum snow-covered albedos of non-forest types are typically higher than those of forest types, showing the shading effect of the density and vertical structure of canopy on snow cover. Forest shading is caused by leaves, stems, branches and trunks, and it has a direct and quantifiable effect on albedo. Although the spatial distribution of albedo generally follows the patterns of land cover type (Jin et al., 2002), some land surface models (LSMs) do not consider the vegetation effect on snow albedo or use unrealistic vegetation parameters - thus resulting in no significant differences in snow-covered albedo over different land surface. In numerical models, albedo under snow condition is usually parameterized through separate treatments for different surfaces (i.e., snow-covered versus snow-free), which are weighted by the snow cover fraction (see Qu and Hall, 2007). Thus, the snow cover fraction is also important for accurate calculation of albedo. Essery (2013) pointed out that some climate models still used unrealistic vegetation parameters or distributions, and improved understanding of snow and radiation interactions with forest canopies was required.

In this study, we examine how vegetation effects can be adequately considered for computation of albedo during winter in the Noah land surface model with multiple physics options (Noah-MP) (Niu et al., 2011; Yang et al., 2011). In the Noah-MP, the formula for albedo includes a sum of leaf area index (LAI) and stem area index (SAI). The details on how LAI and SAI depend on albedo are explained in Sect. 3.2.1. In most cases, the grid box values of LAI and SAI in winter are set to the same minimum values over all vegetation types (i.e., $\mathrm{LAI}_{\min }=0.05$ and $\mathrm{SAI}_{\min }=0.01$ ) and are too low compared to observations synthesized by Asner et al. (2003). The crucial point to note is that both LAI and SAI are represented as photosynthetically active structures in the NoahMP. As photosynthetically active leaves and stems are absent in winter, the model cannot simulate albedo accurately because nonphotosynthetic vegetation structures are not parameterized at all. In winter, these nonphotosynthetic parts are very important for surface albedo through shadowing. Such deficient parameterizations of nonphotosynthetic vegetation structures can be a major cause of the large positive bias errors of albedo in the Noah-MP. Therefore, we improved the model-calculated albedo with a new parameterization of vegetation parameters, which is simple and effective.

\section{Model and data description}

\subsection{The Noah-MP}

The Noah-MP has evolved from the Noah land surface model and has much potential to accelerate physically based ensemble climate prediction model runs and identification of both the optimal scheme combinations and the critical processes controlling the coupling strength (Niu et al., 2011). In this study, the model has been used in offline mode, simulating the land surface processes with atmospheric forcing. The Noah-MP has 12 different scheme sets representing various physical processes. We have selected the default options that were verified for global river basins by Yang et al. (2011). The dynamic vegetation option is employed to assess the minimum leaf and stem area indices. For this study, we have conducted experiments using the BiosphereAtmosphere Transfer Scheme (BATS; Dickinson et al., 1993; Yang et al., 1997) as the option for snow surface albedo. We have also used the Canadian Land Surface Scheme (CLASS; Verseghy, 1991; Verseghy et al., 1993) with new vegetation parameters for testing model performance of albedo. In terms of the albedo options in the Noah-MP, the CLASS scheme simply computes the overall snow albedo depending on fresh snow albedo and snow age while the BATS one calculates snow albedo for direct and diffuse radiation in visible and near-infrared broadband accounting for several additional parameters such as grain size growth, impurity, and especially solar zenith angle (SZA) (Niu et al., 2011).

The computational domain on which we have run the model covers $4000 \mathrm{~km} \times 4000 \mathrm{~km}$, with a grid size of approximately $30 \mathrm{~km}$, in the East Asia region $\left(105-145^{\circ} \mathrm{E}, 20\right.$ $60^{\circ} \mathrm{N}$ ). However, most analyses have been performed north of $40^{\circ} \mathrm{N}$, where snow falls moderately. The model has run during the years 2001-2010. Soil temperature, soil moisture, and snow cover have been initialized by having a spin-up period of 6 months. Simulations started on 00:00 UTC 1 June.

\subsection{Data sets}

\subsubsection{Atmospheric forcing}

Atmospheric data are required to force the land surface processes in LSMs. For the Noah-MP, the Global Land Data Assimilation System (GLDAS) (Rodell et al., 2004) data have been used to drive the model during the period 20012010. The atmospheric forcing data set is a combination of NOAA/GDAS atmospheric analysis field, spatially and temporally disaggregated NOAA Climate Prediction Center Merged Analysis of Precipitation (CAMP) fields, and observation-based downward shortwave and longwave radiation fields derived using the method of the Air Force Weather Agency AGRicultural METeorological modeling system (AGRMET). The data consist of eight forcing fields: precipitation, downward shortwave and longwave radiation, 
Table 1. The USGS land cover classification.

\begin{tabular}{ll}
\hline 1. Urban and built-up land & 15. Mixed forest \\
2. Dryland cropland and pasture & 16. Water bodies \\
3. Irrigated cropland and pasture & 17. Herbaceous wetland \\
4. Mixed dryland/irrigated cropland and pasture & 18. Wooded wetland \\
5. Cropland/grassland mosaic & 19. Barren or sparsely vegetated \\
6. Cropland/woodland mosaic & 20. Herbaceous tundra \\
7. Grassland & 21. Wooded tundra \\
8. Shrubland & 22. Mixed tundra \\
9. Mixed shrubland/grassland & 23. Bare ground tundra \\
10. Savanna & 24. Snow or ice \\
11. Deciduous broadleaf forest & 25. Playa \\
12. Deciduous needleleaf forest & 26. Lava \\
13. Evergreen broadleaf forest & 27. White sand \\
14. Evergreen needleleaf forest &
\end{tabular}

near-surface air temperature, near-surface specific humidity, near-surface zonal and meridional wind, and surface pressure. The temporal resolution is $3 \mathrm{~h}$ and the spatial resolution is $0.25^{\circ}$.

\subsubsection{MODIS albedo}

The MODerate-resolution Imaging Spectroradiometer (MODIS) albedo product (MCD43C3), produced by data from both TERRA and AQUA polar-orbiting satellites, is evaluated every 16 days in a Level 3 data set, projected onto a 0.05 latitude-longitude Climate Modelling Grid (CMG) (Schaaf et al., 2002). We use total shortwave broadband for white-sky albedo (bihemispherical reflectance under conditions of isotropic illumination) and quality flags that include the percentage of snow and the percentage contribution of fine-resolution data. Cescatti et al. (2012) validated MODIS albedo retrievals against in situ measurements across 53 FLUXNET sites and found a good agreement in mean yearly values between retrievals and measurements with a high correlation $\left(r^{2}=0.82\right)$.

\subsubsection{USGS land use and land cover}

The yearly MODIS land cover and land use data within the International Geosphere-Biosphere Programme (IGBP) global vegetation classification scheme have been slightly modified to fit into the land cover classification of the US Geological Survey (USGS) (Anderson, 1976). In this study, land cover types are grouped into 27 types according to the USGS classification, as shown in Table 1.

\section{Results}

\subsection{Physical properties of snow-covered vegetation}

For figuring out the difference of albedo among various vegetation types, we select 10 areas within $40-60^{\circ} \mathrm{N}$ and $105-$ $145^{\circ} \mathrm{E}$ (Fig. 1) where a single type or two similar types of vegetation occupy more than $70 \%$ in each area (Table 2 ). In order to minimize the effects of snow cover change, we have averaged the MODIS white-sky albedo over dominating vegetation type in each area for wintertime (i.e., 273-129 Julian days) in total shortwave broadband during 10 years (20012010) with a $100 \%$ snow cover fraction (SCF) (see Fig. 2). The number of days in each area with a $100 \%$ SCF is sufficient for comparison, as shown in Table 3. It is evident that the snow-covered albedo values are distributed over a wide range and relatively low for various forest types. The snowcovered surface albedo is different when the snow is over the ground surface versus over the canopy, mainly due to an uneven structure of the canopy and the forest shading effect. When the growing season is over, leaves disappear for some vegetation (e.g., deciduous trees) and remain unchanged for others (e.g., evergreen trees), while most of stems remain unchanged - reaching the minimum values. Thus, this change at the end of the growing season and the amount of stems depend on vegetation types and make distinctions of albedos over the forest types in winter.

Compared to the MODIS observation, the Noah-MP snow-covered albedos are overestimated over all vegetation types in winter and have little difference between forest and short vegetation (see Table 4). This is mainly due to the use of LAI and SAI, which are not able to quantify leaves and stems representing the forest masking in winter. In the NoahMP, LAI and SAI are computed as follows:

$\mathrm{LAI}=\max \left(m_{\text {leaf }} \cdot \mathrm{LAPM}_{\mathrm{LAI}} \mathrm{LA}_{\text {min }}\right)$,
$\mathrm{SAI}=\max \left(m_{\text {stem }} \cdot \mathrm{SAPM}, \mathrm{SAI}_{\text {min }}\right)$, 
Table 2. Geographic location, vegetation type, and percentage of dominant vegetation type for selected areas.

\begin{tabular}{ccclc}
\hline Area & Longitude & Latitude & Vegetation type & Percentage \\
\hline 1 & $105.00-107.25^{\circ} \mathrm{E}$ & $56.50-58.25^{\circ} \mathrm{N}$ & Mixed forest & 71.4 \\
2 & $116.25-120.00^{\circ} \mathrm{E}$ & $55.50-57.75^{\circ} \mathrm{N}$ & $\begin{array}{l}\text { Shrubland } \\
\text { Mixed shrubland/grassland }\end{array}$ & 80.0 \\
& & & & 85.7 \\
3 & $122.50-127.75^{\circ} \mathrm{E}$ & $57.50-60.00^{\circ} \mathrm{N}$ & Deciduous needleleaf forest & 90.4 \\
4 & $133.75-136.50^{\circ} \mathrm{E}$ & $55.75-60.00^{\circ} \mathrm{N}$ & Deciduous needleleaf forest & 82.6 \\
5 & $138.50-140.75^{\circ} \mathrm{E}$ & $56.25-60.00^{\circ} \mathrm{N}$ & Shrubland & \\
& & & Mixed shrubland/grassland & 93.5 \\
6 & $121.25-126.50^{\circ} \mathrm{E}$ & $53.75-55.75^{\circ} \mathrm{N}$ & Deciduous needleleaf forest & 81.7 \\
7 & $107.75-111.50^{\circ} \mathrm{E}$ & $49.00-51.00^{\circ} \mathrm{N}$ & Mixed forest & 97.2 \\
8 & $113.75-117.75^{\circ} \mathrm{E}$ & $45.00-49.00^{\circ} \mathrm{N}$ & Grassland & 77.2 \\
9 & $123.75-127.75^{\circ} \mathrm{E}$ & $46.75-50.25^{\circ} \mathrm{N}$ & Dryland cropland and pasture & 93.8 \\
10 & $135.00-137.75^{\circ} \mathrm{E}$ & $45.00-47.75^{\circ} \mathrm{N}$ & Mixed forest &
\end{tabular}

Table 3. Number of days with a $100 \%$ snow cover fraction (SCF) in each area in the period of 2001-2010.

\begin{tabular}{rcccccccccc}
\hline Area & 1 & 2 & 3 & 4 & 5 & 6 & 7 & 8 & 9 & 10 \\
\hline No. of days & 1483 & 6159 & 13235 & 12391 & 4033 & 8201 & 328 & 9318 & 7973 & 248 \\
\hline
\end{tabular}

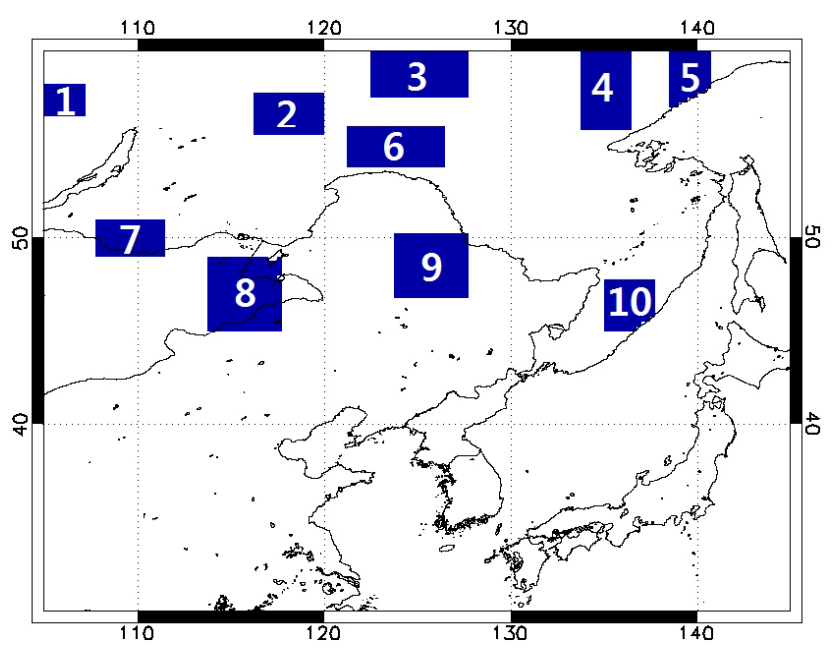

Figure 1. Geographical locations of the study domain. Each blue area has a dominant vegetation type as explained in Table 2.

where $m_{\text {leaf }}\left(m_{\text {stem }}\right)$ is the leaf (stem) mass per unit area (in $\mathrm{g} \mathrm{m}^{-2}$ ) and LAPM (SAPM) is the leaf (stem) area per unit mass (in $\mathrm{m}^{2} \mathrm{~g}^{-1}$ ). The subscript min implies the minimum value. The default values of $\mathrm{LAI}_{\min }$ and $\mathrm{SAI}_{\min }$ are 0.05 and $0.01 \mathrm{~m}^{2} \mathrm{~m}^{-2}$, respectively, for all vegetation types. During most of the winter period, both LAI and SAI remain equal to their minimum values (i.e., $\mathrm{LAI}_{\min }$ and $\mathrm{SAI}_{\min }$ ). Tian et al. (2004) indicated that discrepancies in the winter albedos between the MODIS observation and LSMs were related to the uncertainty in quantifying LAI and SAI in the model. They also mentioned that stems would have different single-scattering albedo than green leaves, and hence it might be inadequate for the model to treat LAI and SAI the same way in the albedo parameterization.

Figure 3 shows a monthly averaged LAI, calculated from Noah-MP, during the period of 2001-2010 for deciduous broadleaf forest (Fig. 3a), deciduous needleleaf forest (Fig. 3b), and evergreen needleaf forest and mixed forest (Fig. 3c). The red lines represent the minimum, mean, and maximum LAI of the reference values from Asner et al. (2003) for each vegetation type. It is notable that the model-evaluated LAI values are much smaller than the reference values for all vegetation types in winter. In Fig. 4, the forest SAI has a seasonal cycle in the Noah-MP, but the magnitude is negligibly small.

The LAI and SAI in Figs. 3 and 4 have large seasonal variations, even in the case of evergreen needleleaf forest. Such large seasonal variations are directly related to the leaf and stem mass, represented by Eqs. (1) and (2) - see Appendix A for the detailed calculation steps. The leaf and stem mass are reduced in winter because they consider the photosynthetic capacity. However, for calculating albedo, the vegetation structure is more important than the photosynthetic capacity, especially in winter.

As previously stated, both LAI and SAI are linked to photosynthetic activeness in the Noah-MP. Compared to the reference value of $\mathrm{LAI}_{\min }$ (e.g., Asner et al., 2003), the model-calculated $\mathrm{LAI}_{\min }$ is highly underestimated for all forest types during winter, and $\mathrm{SAI}_{\min }$ is even lower than $\mathrm{LAI}_{\min }$. These uncertainties are due to disregard of nonphotosynthetic process in defining LAI in the model. Note that the observed LAI represents all leaves regardless of photosynthetic capacity. Hence, the observed LAI is higher than the model-evaluated LAI. Actually, the structure and density of all leaves and stems have effects on albedo. Observed LAI 


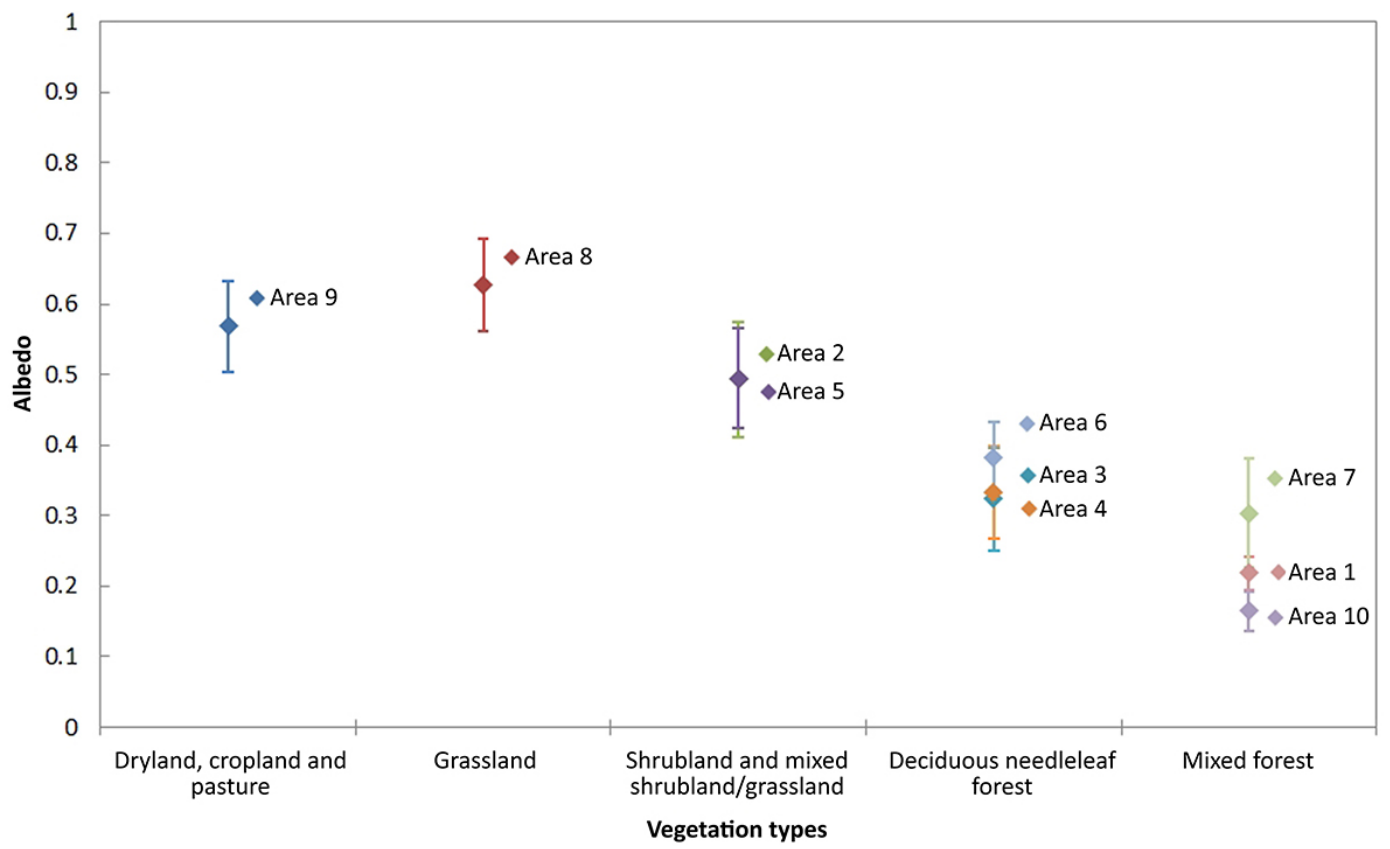

Figure 2. The MODIS white-sky albedo for total shortwave broadband averaged for winter time in 2001-2010 (dots) and corresponding standard deviation (bars) when snow cover fraction equals $100 \%$. Descriptions on the areas are provided in Fig. 1 and Table 2.

Table 4. The values of mean and standard deviation (SD) of snow albedo from the MODIS observation and the Noah-MP results for the shortwave broadband for different categories of the MODIS land cover. The data are averaged for winter time in 2001-2010 over each vegetation type within $40-60^{\circ} \mathrm{N}$ and $105-145^{\circ} \mathrm{E}$ with corresponding SD when SCF equals $100 \%$ and other snow conditions are the same.

\begin{tabular}{lccllc}
\hline \multirow{2}{*}{ MODIS land cover } & \multicolumn{2}{c}{ MODIS } & & \multicolumn{2}{c}{ Noah-MP } \\
\cline { 2 - 3 } \cline { 5 - 6 } & Mean & SD & & Mean & SD \\
\hline Dryland cropland and pasture & 0.515 & 0.088 & & 0.795 & 0.012 \\
Grassland & 0.595 & 0.080 & & 0.787 & 0.020 \\
Shrubland & 0.432 & 0.079 & & 0.805 & 0.029 \\
Mixed shrubland/grassland & 0.474 & 0.085 & & 0.806 & 0.026 \\
Deciduous broadleaf forest & 0.428 & 0.076 & & 0.748 & 0.075 \\
Deciduous needleleaf forest & 0.346 & 0.080 & & 0.678 & 0.134 \\
Evergreen needleleaf forest & 0.296 & 0.097 & & 0.761 & 0.069 \\
Mixed forest & 0.334 & 0.093 & & 0.721 & 0.115 \\
\hline
\end{tabular}

includes all leaves, regardless of their ability to express photosynthesis; hence it is higher than the one evaluated by the model, which is related to photosynthesis. Therefore, it is necessary to properly parameterize the vegetation effects on the snow-covered albedo.

\subsection{Parameterization of the vegetation effects on the snow surface albedo}

We have introduced new parameters in the model - leaf index (LI) and stem index (SI). LI represents a sum of LAI defined in the Noah-MP (i.e., photosynthetic leaves) and LAI of nonphotosynthetic leaves. We have substituted LI with the reference minimum values (see Asner et al., 2003) for four forest types, as shown in Table 5 in Sect. 3.2.2, in order to draw a realistic SI effect. SI represents a sum of SAI defined in the model (i.e., photosynthetic stems) and SAI of nonphotosynthetic stems. In defining SI, we assumed that trees were mature and focused on winter when the growing season is over; thus SI has no seasonal cycle. To figure out how albedo responds to stems, we examine the sensitivity of winter albedo to SI over forest types in the Noah-MP and then validate albedo with the optimal SI value.

\subsubsection{Sensitivity of the snow-covered albedo to SI}

We have focused on testing the albedo scheme in idealized cases. To avoid the effects of other parameters such as snow cover fraction and snow age, we have assumed fresh snow with the snow cover fraction set to 1 , the wetted fraction of both LI and SI to 1, and snow depth to $1 \mathrm{~m}$. We have imposed SI to vary from 0.1 to 10.0 with an interval of 0.1 , as well as SZA 0, 30, 45, 60 and $75^{\circ}$. In the Noah-MP, options for two-stream radiation transfer decide the values of canopy gap probability for direct and diffuse beam. Here the canopy gap probability is defined as the chance that a photon 


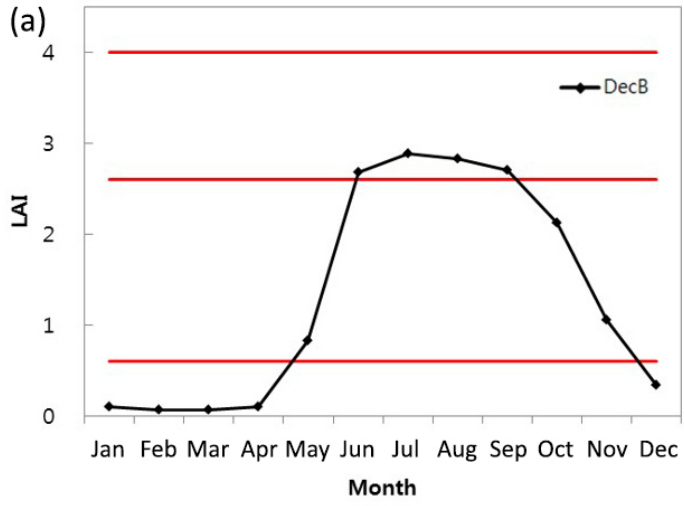

(b)
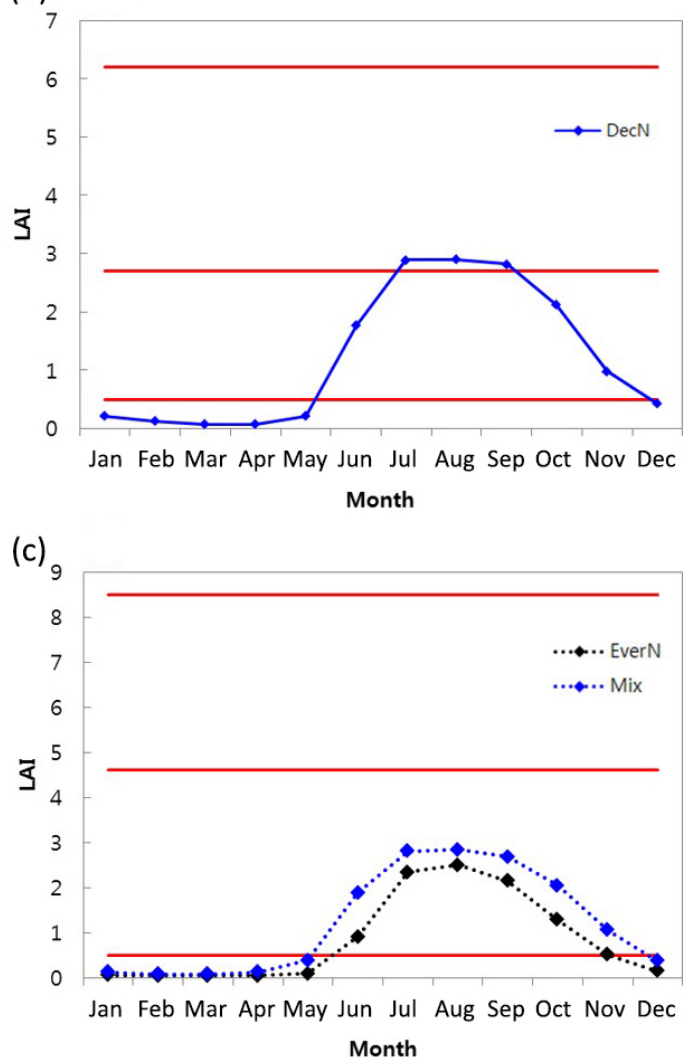

Figure 3. Monthly averaged LAI in the Noah-MP during the period of 2001-2010 for (a) deciduous broadleaf forest (DecB), (b) deciduous needleleaf forest (DecN), (c) evergreen needleleaf forest (EverN), and mixed forest (Mix). The red lines represent the minimum, mean, and maximum LAI of the reference values. In (c), the reference values are shown only for EverN.

penetrates through the vegetation without being intercepted by any crowns (Niu and Yang, 2004). The modified twostream approximation (MTSA), which is the first option of the two-stream radiation transfer scheme, explicitly includes the three-dimensional structure of the vegetation canopy by calculating the total canopy gap probability for direct beam, $P_{\mathrm{c}}$. It is equal to the sum of the between-crown gap probability, $P_{\mathrm{bc}}$, which is a function of crown geometric proper-

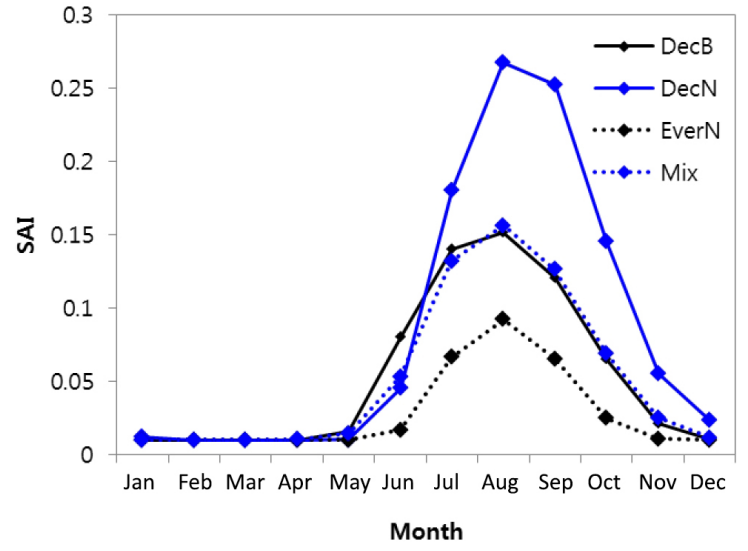

Figure 4. Monthly averaged SAI in the Noah-MP during the period of 2001-2010 for deciduous broadleaf forest (DecB), deciduous needleleaf forest (DecN), evergreen needleleaf forest (EverN), and mixed forest (Mix).

ties and the SZA, and the within-crown gap probability, $P_{\mathrm{wc}}$, which is parameterized on the basis of a modified version of Beer's law:

$$
\begin{aligned}
& P_{\mathrm{bc}}=e^{-\rho_{\mathrm{t}} \pi R^{2} / \cos \left(\theta^{\prime}\right)}, \\
& P_{\mathrm{wc}}=\left(1-P_{\mathrm{bc}}\right) e^{-0.5 F_{\mathrm{a}} H_{\mathrm{d}} / \cos \theta}, \\
& P_{\mathrm{c}}=\min \left(1-f_{\mathrm{veg}}, P_{\mathrm{bc}}+P_{\mathrm{wc}}\right),
\end{aligned}
$$

where $\rho_{\mathrm{t}}$ is the crown density (stems $\mathrm{m}^{-2}$ ), $R$ is the horizontal crown radius, $\theta$ is the solar zenith angle, $\theta^{\prime}=$ $\tan ^{-1}[(b / R) \tan \theta]$, and $b$ is the vertical crown radius. $F_{\text {a }}$ is the foliage area volume density $\left(\mathrm{m}^{-1}\right)$ and is equal to $\operatorname{LSAI} /\left(\frac{4}{3} \pi R^{2} b \rho_{\mathrm{t}}\right)$, where $\mathrm{LSAI}$ is the effective leaf and stem area index, through which the effect of clumping of needles into shoots is included (Chen et al., 1991; Niu and Yang, 2004). $H_{\mathrm{d}}$ is the crown depth. $f_{\text {veg }}$ is the green vegetation fraction and ranges from 0 to 1 . Therefore, if we apply new LI and SI, LSAI is changed and then the canopy gap probability is changed.

Figure 5 depicts the sensitivity of the snow-covered surface albedo and each term in albedo equation in the NoahMP to SI, averaged over four forest types for different SZA. Total albedo by vegetation and ground, $f_{\text {re }}$, is evaluated as

$f_{\mathrm{re}}= \begin{cases}\alpha_{\mathrm{dc}}\left(1-P_{\mathrm{c}}\right)+\alpha_{\mathrm{d}} P_{\mathrm{c}} & \text { (for direct beam) } \\ \alpha_{\mathrm{ic}}\left(1-K_{\mathrm{open}}\right)+\alpha_{\mathrm{i}} K_{\mathrm{open}} & \text { (for diffuse beam) },\end{cases}$

where $\alpha_{\mathrm{d}}$ and $\alpha_{\mathrm{dc}}$ are the direct albedo of the underlying surface and canopy, respectively, and $\alpha_{\mathrm{i}}$ and $\alpha_{\mathrm{ic}}$ are the diffuse albedo of the underlying surface and canopy, respectively. The parameterization of canopy albedo is explained in detail in Sellers (1985). $K_{\text {open }}$ is the between-crown gap probability for diffuse radiation, and here it has been set to 0.05 . Calculation of the total albedo based on the four radiation components, shown in Fig. 5 (i.e., direct versus diffuse albedo 

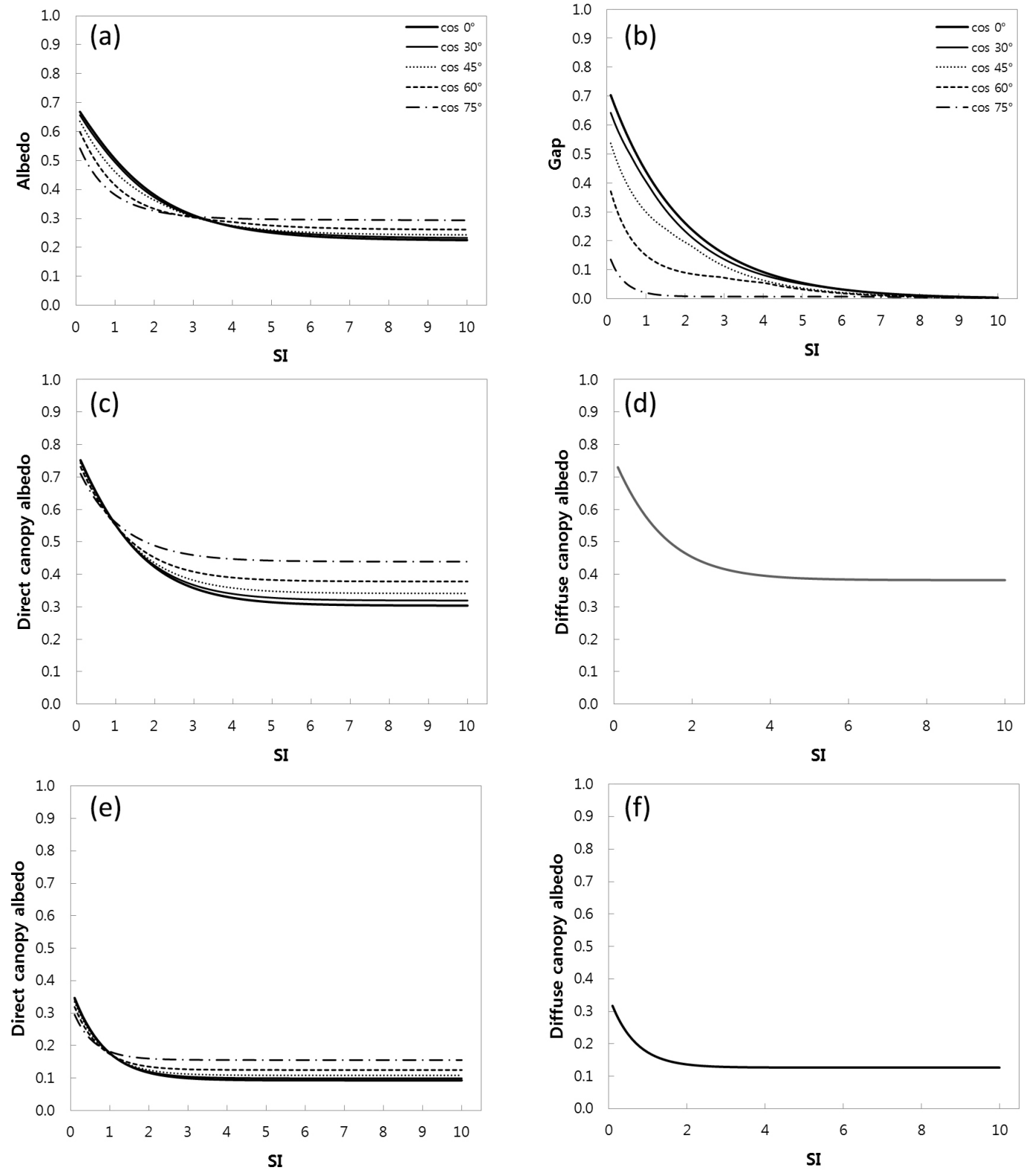

Figure 5. Sensitivity of the snow-covered surface albedo and each term in the albedo equation in the Noah-MP to SI averaged over four forest types: (a) total albedo, (b) canopy gap probability, (c) direct albedo and (d) diffuse albedo for visible broadband, and (e) direct albedo and (f) diffuse albedo for near-infrared broadband.

for visible and direct versus diffuse albedo for near-infrared broadband), is explained in detail in Appendix B.

As expected, total albedo over four forest types generally decreases with increasing SI because snow albedo over the vegetated surface is lower than that over the bare soil surface (Fig. 5a). At a fixed SI, albedo represents different patterns for different SZA - with increasing SZA, albedo decreases at relatively low SI while it increases at relatively high SI. Note that there is sufficient ground surface at relatively low SI that can be shaded by the vegetative canopy as SZA increases (Fig. 5b). Thus, at low SI, albedo is highest when the shadow area of underlying snow-covered surface is the smallest, that is, at local noon. Wang and Zeng (2010) also pointed out this feature using the Community Land Model 3.0. Canopy albedo also decreases with SI due to the increasing optical depth of direct and diffuse beam through leaf and stem area (Fig. 5c-f). 
Table 5. Minimum value of LAI, reference values (LI), the default minimum value of SAI, and optimized SI values (in bold) for selected USGS land cover type (forest). The optimized values are based on the sensitivity test.

\begin{tabular}{lcccc}
\hline USGS land cover type & $\begin{array}{c}\text { Minimum } \\
\text { of LAI } \\
\text { (default) }\end{array}$ & $\begin{array}{c}\text { LI } \\
\text { (reference) }\end{array}$ & $\begin{array}{c}\text { Minimum } \\
\text { of SAI } \\
\text { (default) }\end{array}$ & $\begin{array}{c}\text { SI } \\
\text { (optimized) }\end{array}$ \\
\hline 11. Deciduous broadleaf forest & 0.05 & 0.6 & 0.01 & $\mathbf{1 . 3}$ \\
12. Deciduous needleleaf forest & 0.05 & 0.5 & 0.01 & $\mathbf{1 . 5}$ \\
14. Evergreen needleleaf forest & 0.05 & 0.5 & 0.01 & $\mathbf{2 . 3}$ \\
15. Mixed forest & 0.05 & 0.5 & 0.01 & $\mathbf{2 . 0}$ \\
\hline
\end{tabular}

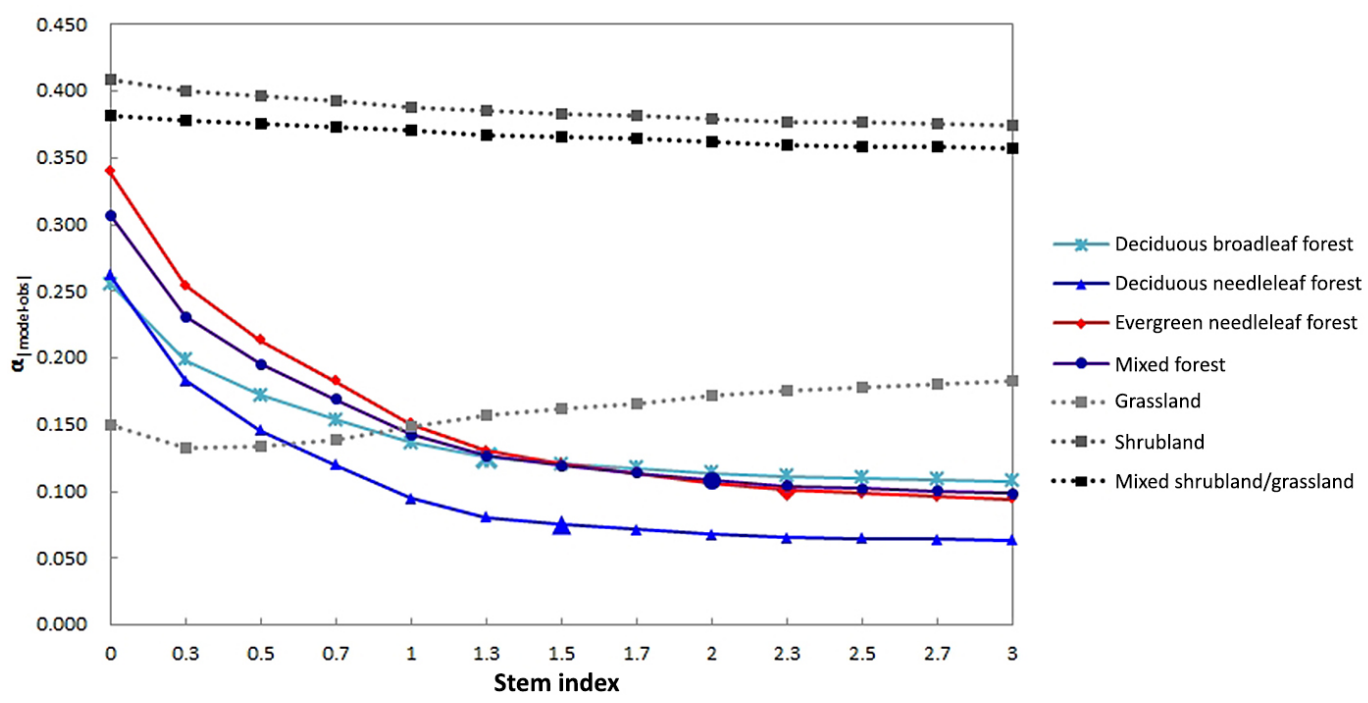

Figure 6. Sensitivity of the winter-averaged albedo to SI over four forest types and three short vegetation types in the Noah-MP for 20012010. The optimized value for each forest type is indicated with a larger symbol.

\subsubsection{Validation of surface albedo with the optimal SI value}

For quantifying the forest shading effect through SI in winter, we have compared the Noah-MP albedo with observations. We have performed model runs by repeatedly changing SI from 0.0 to 3.0 in order to find the optimal SI for each forest type that is able to reduce the bias of albedo between observation and model output. LAI and SAI were used to calculate fluxes of carbon, radiation, turbulent heat, etc., during the growing season. Hence, we have applied LI and SI when the growing season index was off. Albedo has then been averaged for 10 years in specific winter days (i.e., 337, 353, and 1, 17, and 33 Julian days) for vegetation types in the East Asia region, in order to compare with the MODIS 16-day observations. We have to priorly evaluate LI for drawing realistic SI effect because LI and SI are considered together for calculating albedo. Here we have assigned the observation values (Asner et al., 2003) to the LI values. Asner et al. (2003) collected more than 1000 estimated LAI from literature and then constructed a global LAI data set through a statistical analysis. The LAI data set of forest types has been compiled from plenty of robust samples; thus they are sufficiently reliable to be used as the reference values of LI.

Figure 6 shows the bias errors of albedo between observations and model output (i.e., absolute values of model minus observation) with SI values for four forest types (i.e., deciduous broadleaf, deciduous needleleaf, evergreen needleleaf, and mixed forest) and three short vegetation types (i.e., grassland, shrubland, and mixed shrubland/grassland). In case of forest types, the bias errors of albedo decrease with increasing SI. On the contrary, the bias errors of albedo for short vegetation types decrease slightly or even increase with increasing SI. Since short vegetation does not have high SI in winter, modification of albedo over short vegetation by increasing SI is meaningless. The optimized SI values, effective for reduction of bias errors in albedo, are 1.3 for deciduous broadleaf forest, 1.5 for deciduous needleleaf forest, 2.3 for evergreen needleleaf forest, and 2.0 for mixed forest (see Table 5). The bias errors of albedo decrease very slowly after a certain value of SI; hence SI is considered to be optimized when the difference of bias between two consecutive SI is less than 0.005 . The other land cover types are not optimized and the default values of $\mathrm{SAI}_{\min }$ are used. The reason why the 

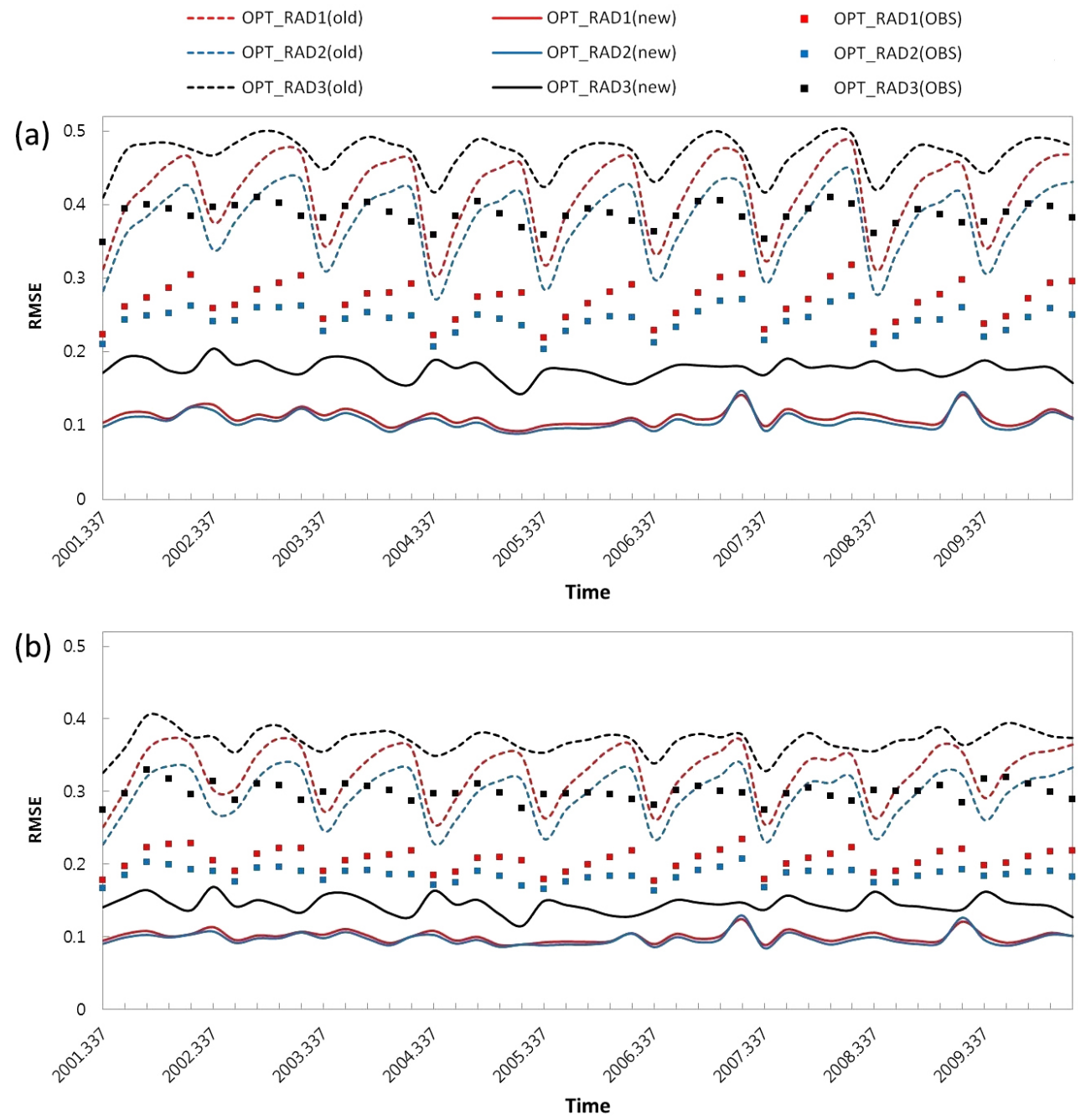

Figure 7. Comparison of RMSE values of albedo with the original minimum value of LAI and SAI (dashed lines) versus new LI and SI (solid lines) versus observed LAI and prescribed SAI (square symbols) for three radiation options for (a) BATS and (b) CLASS radiation schemes. OPT_RAD1 is MTSA, OPT_RAD2 is two-stream radiation option with no canopy gap, and OPT_RAD3 is the scheme that calculates the gap from vegetation fraction.

errors do not decrease below a certain level is possibly due to other parameters such as snow age, fresh snow albedo, and snow cover fraction that are not validated in the model.

The model performance with the new LI and SI has been evaluated by calculating the root mean square errors (RMSEs) of albedo against observation (MODIS), as shown in Fig. 7. Here, the RMSEs of albedo, simulated with the observed LAI and the prescribed monthly SAI, are also depicted (square symbols). For the observed LAI, we used the AVHRR GIMSS LAI3g data and took an average for winter during 2001-2010 for each vegetation type within the domain of $40-60^{\circ} \mathrm{N}$ and $105-145^{\circ} \mathrm{E}$. Since SAI is not observed, we have taken the prescribed monthly SAI value in the Noah-MP for each vegetation type. Even with the observed vegetation parameter, the RMSEs in simulated albedo are still significant. We have also calculated the RMSEs of albedo, using the LAI data from Lawrence and Chase (2007) - another good source of LAI but for eight plant functional types rather than five land cover types used in this study. The simulated albedo with these LAI showed larger RMSEs than those with satellite-retrieved LAI (not shown).

It is noteworthy that the performance of the Noah-MP in calculating albedo has greatly improved with the new parameterization - RMSE has been reduced by approximately $69 \%$. Although we optimized SI with the MTSA, Fig. 7 shows how the parameterization affects albedo with other options as well. The simulations of albedo are improved for all two-stream radiation transfer and snow surface albedo schemes - BATS (Fig. 7a) and CLASS (Fig. 7b) with RMSEs reduced by approximately $70 \%$ on average. Albedo with other radiation options is also overestimated, due to underestimated LAI and SAI. 
There are three radiation options in the Noah-MP for calculating energy fluxes (see Fig. 7) - the first is MTSA, employed for parameterization in this study, which calculates canopy gaps from three-dimensional structure and solar zenith angle (OPT_RAD1). The second option is two-stream radiation option with no canopy gap, which means leaves are evenly distributed within the grid cell with a $100 \%$ vegetation fraction (OPT_RAD2). The last is the tile approach that computes energy fluxes in vegetated fraction and bare fraction separately and then sums them up weighted by fraction (OPT_RAD3). The optimal LI and SI obtained through the MTSA had the similar improving effect on albedo when applied to the other options. The RMSEs with the original minimum values of LAI and SAI increase until mid-winter (e.g., the 17th Julian day) and decrease after that. During the winter, albedo is dominantly influenced by the snow cover and forest masking (Bonan, 2008; Essery et al., 2009; Brovkin et al., 2013). The Noah-MP overestimates snow cover fraction and underestimates vegetation parameters (i.e., $\mathrm{LAI}$ and $\mathrm{SAI}$ ) related to albedo; therefore, albedo is greatly overestimated. This error is significantly reduced by applying new parameters that consider all the forest structure effect with realistic values.

\section{Conclusions}

In winter, albedo has a large variation due to snow cover; however, in forest regions, the snow-covered albedo remains low for two reasons. First, when the snow covers a for- est canopy, the incident radiation is diffused rather than reflected due to irregular surfaces. Second, vegetation shields the snow-covered surfaces. In addition, in regions with average December-January-February temperatures greater than $-1^{\circ} \mathrm{C}$, the forest cover effect becomes dominant and accelerates snowmelt from increasing longwave radiation; hence forest cover reduces snow duration by 1-2 weeks compared to adjacent open areas (Lundquist et al., 2013). This effect reduces albedo further, causing more radiation to be absorbed by the ground - thus resulting in a strong positive feedback (Qu and Hall, 2007). Therefore, accurate calculation of albedo is very influential in the land surface processes. We have addressed the noticeable relationship between the vegetation types and the snow surface albedo through satellite observations. Nevertheless, in the Noah land surface model with multiple physics options (Noah-MP) as well as many land surface models, albedo was calculated without considering the vegetation effects properly. In order to apply the vegetation effect on the snow-covered albedo, we have introduced new parameters, called leaf index (LI) and stem index (SI). We focused on the SI effect because stems are more critical than leaves in the winter albedo. The performance of the Noah-MP in calculating albedo has remarkably improved with simple parameterization for all radiation options and snow surface albedo schemes. However, there is a limitation to enhancing the accuracy of albedo by changing only vegetation indices. Thus, it is required to assess the other parameters, too, such as snow cover fraction and fresh snow albedo, which are not validated against observations. 


\section{Appendix A: Calculation of the leaf and stem mass}

The simulated LAI and SAI in the Noah-MP have large seasonal variations, even in the case of evergreen forests. This is because LAI and SAI are defined as the photosynthetic active indices. When the growing index is off, both the foliage photosynthesis parameter and the value of the carbon assimilated (CARBFX; $\mathrm{g} \mathrm{m}^{-2}$ ) become zero. Then, the leaf assimilation after removing the respiration losses (ADDNPPLF; $\mathrm{g} \mathrm{m}^{-2}$ ) also becomes zero. Thus, in winter, the leaf mass is reduced. The stem mass is calculated in the same way. The equations for calculating leaf and stem mass are shown in the following:

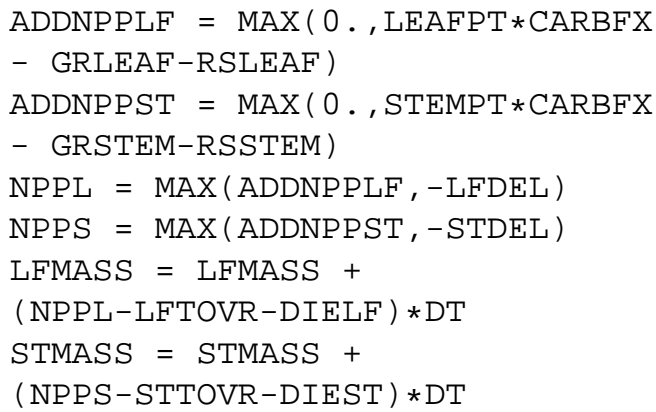

where ADDNPPST is the stem assimilation after removing the respiration losses $\left(\mathrm{g} \mathrm{m}^{-2}\right)$, NPPL(NPPS) is the leaf (stem) net primary productivity $\left(\mathrm{g} \mathrm{m}^{-2} \mathrm{~s}^{-1}\right)$, and LFMASS (STMASS) is the leaf (stem) mass $\left(\mathrm{g} \mathrm{m}^{-2}\right)$. The LEAFPT is fraction of carbon allocated to leaves, and STEMPT is fraction of carbon flux to stem. The GRLEAF (GRSTEM) is the growth respiration rate for leaf (stem) $\left(\mathrm{g} \mathrm{m}^{-2} \mathrm{~s}^{-1}\right)$, RSLEAF is the leaf maintenance respiration per time step $\left(\mathrm{g} \mathrm{m}^{-2}\right)$, and RSSTEM is the stem respiration $\left(\mathrm{g} \mathrm{m}^{-2}\right)$. The LFDEL (STDEL) is the maximum leaf (stem) mass available to change $\left(\mathrm{g} \mathrm{m}^{-2} \mathrm{~s}^{-1}\right)$, LF TOVR (STTOVR) is the leaf (stem) turnover per time step $\left(\mathrm{g} \mathrm{m}^{-2}\right)$, DIELF (DIEST) is the death of leaf (stem) mass per time step $\left(\mathrm{g} \mathrm{m}^{-2}\right)$, and DT is a time step (s).

\section{Appendix B: Calculation of total albedo and weights by the radiation components}

We here discuss how the radiation components in Fig. 5 are weighted to calculate the total albedo. First, the downward solar radiation (SWDOWN; $\mathrm{W} \mathrm{m}^{-2}$ ) is divided into four parts direct visible (SOLAD (1) ) and diffuse visible (SOLAI (1) radiation, and direct near-infrared (SOLAD (2)) and diffuse near-infrared (SOLAI (2) ) radiation, as shown in the following equations:

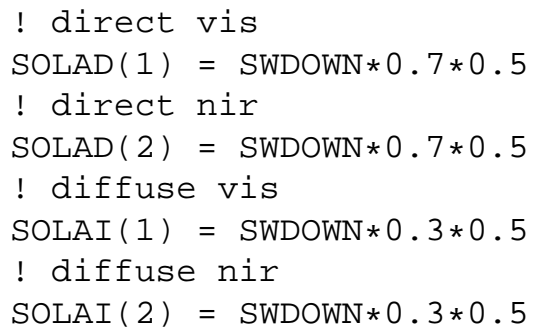

Second, four albedo components are weighted to calculate the total radiation as follows:

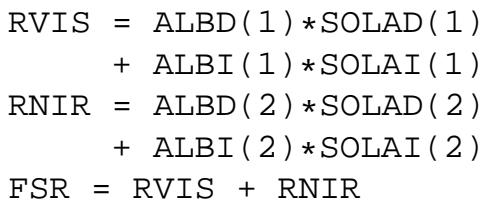

where ALBD (1) and ALBD (2) are albedos from direct visible bands and direct near-infrared bands, respectively, and ALBI (1) and ALBI (2) are albedos from diffuse visible bands and diffuse near-infrared bands, respectively. RVIS and RNIR are reflected radiative fluxes from visible bands and near-infrared bands, respectively, and FSR is total reflected radiative flux. Finally, the total albedo is obtained through the following formula:

$$
\text { ALBEDO }=\text { FSR/SWDOWN, }
$$

as the ratio of total reflected radiative flux to the downward solar radiation. 
Acknowledgements. This work is supported by the National Research Foundation of Korea grant (no. 2009-0083527) funded by the Korean government (MSIP). The authors thank Seungbum Hong at the National Institute of Ecology, Korea, for assistance with the Noah-MP.

Edited by: J. Fyke

\section{References}

Anderson, J. R.: A Land Use and Land Cover Classification System for Use With Remote Sensor Data, Vol. 964, US Government Printing Office, Washington, 1976.

Asner, G. P., Scurlock, J. M., and Hicke, J. A.: Global synthesis of leaf area index observations: implications for ecological and remote sensing studies, Global Ecol. Biogeogr., 12, 191-205, 2003.

Bonan, G. B.: Forests and climate change: forcings, feedbacks, and the climate benefits of forests, Science, 320, 1444-1449, 2008.

Brovkin, V., Boysen, L., Raddatz, T., Gayler, V., Loew, A., and Claussen, M.: Evaluation of vegetation cover and land-surface albedo in MPI-ESM CMIP5 simulations, J. Adv. Model. Earth Syst., 5, 48-57, doi:10.1029/2012MS000169, 2013.

Cescatti, A., Marcolla, B., Vannan, S. K. S., Pan, J. Y., Roman, M. O., Yang, X., Ciais, P., Cook, R. B., Law, B. E., Matteucci, G., Migliavacca, M., Moors, E., Richardson, A. D., Seufert, G., and Schaaf, C. B.: Intercomparison of MODIS albedo retrievals and in situ measurements across the global FLUXNET network, Remote Sens. Environ., 121, 323-334, 2012.

Chen, J. M., Balck, T. A., and Adams, R. S.: Evaluation of hemispherical photography for determining plant area index and geometry of a forest stand, Agr. Forest Meteorol., 56, 129-143, 1991.

Dickinson, R. E., Henderson-Sellers, A., and Kennedy, P. J.: Biosphere-Atmosphere Transfer Scheme (BATS) version 1e as coupled to the NCAR Community Climate Model, NCAR Tech. Note NCAR/TN-387+STR, Natl. Cent. for Atmos. Res., Boulder, CO, 80 pp., 1993.

Essery, R.: Large-scale simulations of snow albedo masking by forests, Geophys. Res. Lett., 40, 5521-5525, doi:10.1002/grl.51008, 2013.

Essery, R., Rutter, N., Pomeroy, J., Baxter, R., Stahli, M., Gustafsson, D., Barr, A., Bartlett, P., and Elder, K.: An evaluation of forest snow process simulations, B. Am. Meteorol. Soc., 90, 11201135, 2009.

Gao, F., Schaaf, C. B., Strahler, A. H., Roesch, A., Lucht, W., and Dickinson, R.: MODIS bidirectional reflectance distribution function and albedo Climate Modeling Grid products and the variability of albedo for major global vegetation types, J. Geophys. Res., 110, D01104, doi:10.1029/2004JD005190, 2005.

Hardy, J. P., Melloh, R., Robinson, P., and Jordan, R.: Incorporating effects of forest litter in a snow process model, Hydrol. Process., 14, 3227-3237, 2000.
Henderson-Sellers, A. and Wilson, M. F.: Surface albedo data for climatic modeling, Rev. Geophys., 21, 1743-1778, doi:10.1029/RG021i008p01743, 1983.

Jin, Y., Schaaf, C. B., Gao, F., Li, X., Strahler, A. H., Zeng, X., and Dickinson, R. E.: How does snow impact the albedo of vegetated land surfaces as analyzed with MODIS data?, J. Geophys. Res., 29, 12.1-12.4, doi:10.1029/2001GL014132, 2002.

Lawrence, P. J. and Chase, T. N.: Representing a new MODIS consistent land surface in the Community Land Model (CLM 3.0), J. Geophys. Res., 112, G01023, doi:10.1029/2006JG000168, 2007.

Lundquist, J. D., Dickerson-Lange, S. E., Lutz, J. A., and Cristea N. C.: Lower forest density enhances snow retention in regions with warmer winters: A global framework developed from plot-scale observations and modeling, Water Resour. Res., 49, 6356-6370, doi:10.1002/wrcr.20504, 2013.

Niu, G.-Y. and Yang, W.-L.: Effects of vegetation canopy processes on snow surface energy and mass balances, J. Geophys. Res., 109, D23111, doi:10.1029/2004JD004884, 2004.

Niu, G.-Y., Yang, Z.-L., Mitchell, K. E., Chen, F., Ek, M. B., Barlage, M., Kumar, A., Manning, K., Niyogi, D., Rosero, E., Tewari, M., and Xia, Y.: The community Noah land surface model with multiparameterization options (Noah-MP): 1. model description and evaluation with local-scale measurements, J. Geophys. Res., 116, D12109, doi:10.1029/2010JD015139, 2011.

$\mathrm{Qu}, \mathrm{X}$. and Hall, A.: What controls the strength of snow-albedo feedback?, J. Climate, 20, 3971-3981, doi:10.1175/JCLI4186.1, 2007.

Rodell, M., Houser, P. R., Jambor, U., Gottschalck, J., Mitchell, K., Meng, C.-J., Arsenault, K., Cosgrove, B., Radakovich, J., Bosilovich, M., Entin, J. K., Walker, J. P., Lohmann, D., and Toll, D.: The Global Land Data Assimilation System, B. Am. Meteorol. Soc., 85, 381-394, doi:10.1175/BAMS-85-3-381, 2004.

Schaaf, C. B., Gao, F., Strahler, A. H., Lucht, W., Li, X., Tsang, T., Strugnell, N. C., Zhang, X., Jina, Y., Muller, J.-P., Lewis, P., Barnsley, M., Hobson, P., Disney, M., Roberts, G., Dunderdale, M., Doll, C., d'Entremont, R. P., Hu, B., Liang, S., Privette, J. L., and Roy, D.: First operational BRDF, albedo nadir reflectance products from MODIS, Remote Sens. Environ., 83, 135-148, 2002.

Sellers, P. J.: Canopy reflectance, photosynthesis and transpiration, Int. J. Remote Sens., 6, 1335-1372, 1985.

Tian, Y., Dickinson, R. E., Zhou, L., Zeng, X., Dai, Y., Myneni, R. B., Knyazikhin, Y., Zhang, X., Friedl, M., Yu, H., Wu, W., and Shaikh, M.: Comparison of seasonal and spatial variations of leaf area index and fraction of absorbed photosynthetically active radiation from Moderate Resolution Imaging Spectroradiometer (MODIS) and Common Land Model, J. Geophys. Res., 109, D01103, doi:10.1029/2003JD003777, 2004.

Verseghy, D. L.: CLASS-A Canadian land surface scheme for GCMS: I. Soil model, Int. J. Climatol., 11, 111-133, doi:10.1002/joc.3370110202, 1991.

Verseghy, D. L., McFarlane, N. A., and Lazare, M.: CLASS: A Canadian Land Surface Scheme for GCMs. II. Vegetation model and coupled runs, Int. J. Climatol., 13, 347-370, 1993. 
Wang, Z. and Zeng, X.: Evaluation of snow albedo in land models for weather and climate studies, J. Clim. Appl. Meteorol., 49, 363-380, 2010.

Yang, Z.-L., Dickinson, R. E., Robock, A., and Vinnikov, K. Y.: Validation of the snow submodel of the biosphere-atmosphere transfer scheme with Russian snow cover and meteorological observation data, J. Climate, 10, 353-373, 1997.
Yang, Z.-L., Niu, G.-Y., Mitchell, K. E., Chen, F., Ek, M. B., Barlage, M., Longuevergne, L., Manning, K., Niyogi, D., Tewari, M., and Xia, Y.: The community Noah land surface model with multiparameterization options (Noah-MP): 2. Evaluation over global river basins, J. Geophys. Res., 116, D12110, doi:10.1029/2010JD015140, 2011. 